Research article

\title{
Butanol synthesis from ethanol over CuMgAl mixed oxides modified with palladium (II) and indium (III)
}

\author{
Olavo Micali Perrone ${ }^{\mathrm{a}, *}$, Francesco Lobefaro ${ }^{\mathrm{c}}$, Michele Aresta ${ }^{\mathrm{c}}$, Francesco Nocito ${ }^{\mathrm{b}}$, \\ Mauricio Boscolo ${ }^{\mathrm{a}}$, Angela Dibenedetto ${ }^{\mathrm{b}}$ \\ ${ }^{a}$ Department of Chemistry and Environmental Sciences, São Paulo State University (UNESP), Institute of Biosciences, Humanities and Exact Sciences, São José do Rio \\ Preto, SP, Brazil \\ ${ }^{\mathrm{b}}$ Department of Chemistry and CIRCC, University of Bari, Campus Universitario, Via Orabona 4, 70126 Bari, BA, Italy \\ ${ }^{\mathrm{c}} I C^{2} R$, Lab H124, Tecnopolis, via Casamassima km 3, Valenzano 70018, Italy
}

\section{A R T I C L E I N F O}

\section{Keywords:}

Ethanol conversion

Heterogeneous catalysis

Butanol

Copper-hydrotalcite

Indium-hydrotalcite

Palladium-hydrotalcite

\begin{abstract}
A B S T R A C T
Ethanol conversion to butanol was investigated over mixed oxides derived from hydrotalcites modified with copper, palladium or indium. The reaction was carried out in the 403-573 K temperature range using stainless steel reactors. The presence of indium or palladium in the catalyst influences the temperature of reaction so that it was possible obtain butanol at temperature as low as $423 \mathrm{~K}$. This is in line with the fact that the addition of metals with high hydrogen-transfer capacity makes faster all steps of the reaction with great energy saving. The best selectivity to butanol $(65 \%)$ was achieved using In-CuMgAl catalysts with $3 \%$ of ethanol conversion at a temperature as low as $443 \mathrm{~K}$.
\end{abstract}

\section{Introduction}

Ethanol generated from renewable resources is one of the most largely used substitutes of fossil-C feedstock. Ethanol is used as a solvent in several applications and although the use of ethanol in the industry has grown in the past decade the main destination for ethanol is still as fuel for motor cars [1]. Ethanol consumption as a fuel is smaller than its production and a large quantity of ethanol is available and can be used for the production of other chemicals [2]. Currently, the most important chemicals derived from ethanol are acetic acid, ethyl acetate, ethylene, hydrogen, isobutene, acetaldehyde, 1,3-butadiene and butanol [2].

Catalytic conversion of ethanol by aldol reactions into chemicals is known as Guerbet reaction and can be achieved by reaction of ethanol in presence of heterogeneous catalysts under the appropriate conditions of temperature and pressure. The most accepted pathway is based on five steps: (i) dehydrogenation of ethanol to acetaldehyde, (ii) aldol condensation of two acetaldehyde molecules, and two consecutive hydrogenation steps (iv and v) of the dehydrated product (step iii) from the aldol reaction (Scheme 1).

Interest in butanol production has grown over recent years due to its many applications in the paint and solvent industry, manufacture of esters, ethers, acetates and resins [3-5]. But a special interest is placed on its fuel properties such as lower volatility than ethanol, immiscibility with water, not corrosive behavior, high octane rating, high energy content and similarity to gasoline. Currently, most of the worldwide butanol is obtained from fossil-C via petrochemical processes, although there are some pilot scale productions of bio-butanol in Brazil and China [4]. Butanol production from ethanol offers several advantages, especially in the Brazilian context, where one can take advantage of the existing infrastructure of ethanol production, stockage and distribution and its consolidated market. The production of butanol within the biorefinery of sugar cane can also increase its profitability as it is a more suitable product for external markets and renewable raw material for the chemical industry [6].

The high temperature usually required to convert ethanol to butanol is the greatest trouble in this reaction. The aldolic reaction may occur at temperatures lower than the Guerbet-reaction, however, the Guerbet reactions require $>573 \mathrm{~K}$ to occur using only $\mathrm{MgAl}$ oxides. Catalysts to overcome this issue have been proposed [3,7]. Nevertheless, high temperatures [8-10] are still required and in such condition the reaction becomes less controlled due to the occurrence of secondary reactions and the formation of several by-products that increase the postprocess separation cost.

Heterogeneous catalysts from hydrotalcite-like materials can be promising materials since they are easy to synthesize and are composed

\footnotetext{
* Corresponding author at: São Paulo State University (UNESP), Av. Cristóvão Colombo, 2265, São José do Rio Preto 15054-000, São Paulo, Brazil.

E-mail addresses: olavo_perrone@hotmail.com (O.M. Perrone), f.lobefaro@ic2r.com (F. Lobefaro), michele.aresta@ic2r.com (M. Aresta), ncfr01ch@uniba.it (F. Nocito), boscolo@ibilce.unesp.br (M. Boscolo), angela.dibenedetto@uniba.it (A. Dibenedetto)
} 


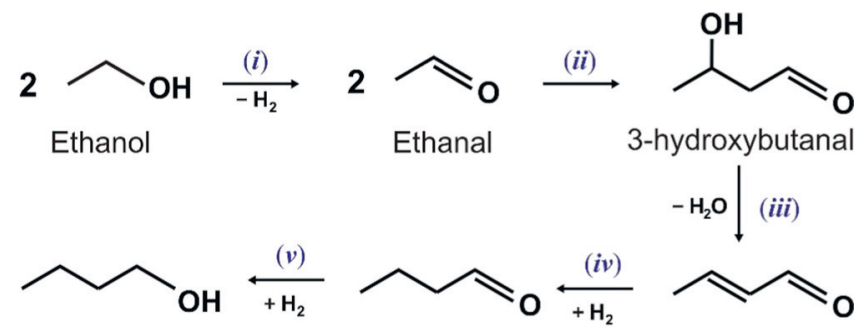

Butanol Butyraldehyde Crotonaldehyde

(i) dehydrogenation; (ii) aldolization (iii) dehydratation (iv) hydrogenation (v)

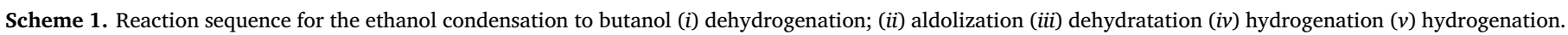

of low-cost materials. The general formula of hydrotalcites (LDH) is $\left[\mathrm{M}_{1-}^{2+} \mathrm{M}_{\mathrm{x}}^{3+}(\mathrm{OH})_{2}\right]^{\mathrm{x}+} \mathrm{A}_{\mathrm{x} / \mathrm{n}}^{\mathrm{n}} \cdot \mathrm{mH}_{2} \mathrm{O}$, where $\mathrm{M}^{2+}$ and $\mathrm{M}^{3+}$ are di- and trivalent metal ions, usually $\mathrm{Mg}^{2+}$ and $\mathrm{Al}^{3+}$, and $\mathrm{A}^{\mathrm{n}-}$ is an intercalated anion between lamellae, usually carbonates. Another important advantage of such material is the possibility of substitution of the initial metals by others modifying the catalytic properties of the catalysts.

In this work we present the behavior of mixed oxide catalysts obtained from calcination of modified LDHs with copper, palladium or indium. These oxides were used to synthesize butanol from ethanol using stainless steel reactors. The reactivity and selectivity of the oxides were assessed. All catalysts were characterized by specific surface area (BET), basicity and acidity. Reaction products were characterized by GC.

\section{Experimental}

\subsection{Catalyst preparation}

LDHs precursors were prepared by co-precipitation method at $\mathrm{pH} 10$ of suitable amounts of metals with a $3: 1 \mathrm{M}^{2+} / \mathrm{M}^{3+}$ molar ratio. Reference material containing copper was made replacing $10 \%$ of $\mathrm{Mg}^{2+}$ ions with $\mathrm{Cu}^{2+}(\mathrm{CuMgAl})$, while materials containing indium or palladium were made by substitutions of $10 \%$ of $\mathrm{Mg}^{2+}$ ions by $\mathrm{Cu}^{2+}$ and $0.5 \%$ of $\mathrm{Cu}$ with $\mathrm{Pd}^{2+}$ (Pd-CuMgAl) or $10 \%$ of $\mathrm{Mg}^{2+}$ ions by $\mathrm{Cu}^{2+}$ and $1 \%$ of $\mathrm{Al}^{3+}$ with $\mathrm{In}^{3+}$ (In-CuMgAl). The precipitation was carried out by slow dropwise addition of the chlorides and nitrates into a wellstirred beaker containing aqueous $\mathrm{Na}_{2} \mathrm{CO}_{3}$. The resulting mixture was kept under agitation at $333 \mathrm{~K}$ for $12 \mathrm{~h}$ in order for the crystals to grow and mature. The precipitate was isolated by filtration and washed five times with distilled water $(100 \mathrm{~mL})$ to remove soluble components and until washings reached a neutral $\mathrm{pH}$. The resulting precipitate was filtered, ground to fine powders and then calcined at $725 \mathrm{~K}$ for $5 \mathrm{~h}$.

The Guerbet reaction was conducted using $3 \mathrm{~mL}$ of bioethanol (anhydrous) and $100 \mathrm{mg}$ of catalyst added in a $100 \mathrm{~mL}$ stainless steel autoclave equipped with a withdrawing valve. N2 was employed to purge oxygen inside the autoclave, the initial reaction pressure was 1 bar and the reaction took place by $5 \mathrm{~h}$. Quantitative determinations on the reaction solutions were performed at fixed intervals of time (withdrawal of $0.1 \mathrm{~mL}$ ) using Hewlett Packard 6850 GC-FID (capillary column Carbowax, $30 \mathrm{~m}, \emptyset 0.25 \mathrm{~mm}$ ). Standards of butanol and acetaldehyde were purchased from Sigma-Aldrich.

The analyses of the acid-base sites were carried out using $\mathrm{NH}_{3}$ or $\mathrm{CO}_{2}$ as probe-gases, respectively. The analysis was performed with a Micromeritics ChemiSorb 2750 equipment, using $100 \mathrm{mg}$ of calcined catalyst sample pretreated under $\mathrm{N}_{2}$ flow $\left(20 \mathrm{~mL} \mathrm{~min}^{-1}\right)$ at $423 \mathrm{~K}$. The Pulse Chemisorption was performed with $\mathrm{NH}_{3}$ or $\mathrm{CO}_{2}$ gases using $\mathrm{He}$ as carrier gas $\left(25 \mathrm{~mL} \mathrm{~min}^{-1}\right)$. BET areas were determined with the same Micromeritics Chemisorb 2750 equipment using 30\% $\mathrm{N}_{2} / 70 \%$ He gas mixture $\left(30 \mathrm{~mL} \mathrm{~min}^{-1}\right)$.

\section{Results and discussion}

\subsection{Catalytic conversion of ethanol}

Guerbet reactions using ethanol were performed using three different catalysts (CuMgAl, Pd-CuMgAl and In-CuMgAl). The reactions were carried out keeping the initial ethanol volume at $3.00 \mathrm{~mL}$ and changing the reaction temperature. In the reaction conditions used in this work, MgAl oxide (3:1) without modification with copper ions did not convert ethanol into butanol in the temperature range 403-533 K. These materials show both Lewis and Brønsted basic sites, and are efficient for the aldolization reaction even at low temperatures [11]. However, they are not efficient in the reaction of dehydrogenation/ hydrogenation that requires higher temperatures and the addition of a catalyst such as copper to occur appropriately $[12,13]$.

Fig. 1 shows that increasing the reaction temperature, the ethanol conversion increases. However, a greater conversion of ethanol does not necessarily mean that the reaction is performing better, since above $500 \mathrm{~K}$ secondary reactions occur and several products are formed making the final separation step energetically and economically expensive. The main products obtained in reactions carried out at high temperatures are: ethyl acetate, diethyl ether, 1,1-diethoxy ethane, 1hexanol, 1-octanol and a mixture of $\mathrm{H}_{2}, \mathrm{CO}, \mathrm{CO}_{2}, \mathrm{CH}_{4}$ and ethylene [14-16]. The detection of $\mathrm{C} 6$ and $\mathrm{C} 8$ species in such reaction show that butanol reacts further on the catalyst surface giving longer chain products. On the other hand, at temperatures lower than $483 \mathrm{~K}$ by-products are less abundant or even are not formed. In this work, the main products below $483 \mathrm{~K}$ analyzed in the condensed phase were ethanal and butanol. Under these reaction conditions low volume of gas was generated and the carbon balance was higher than $90 \%$. The selectivity and yield of the formed products depends on the acid/base characteristics of

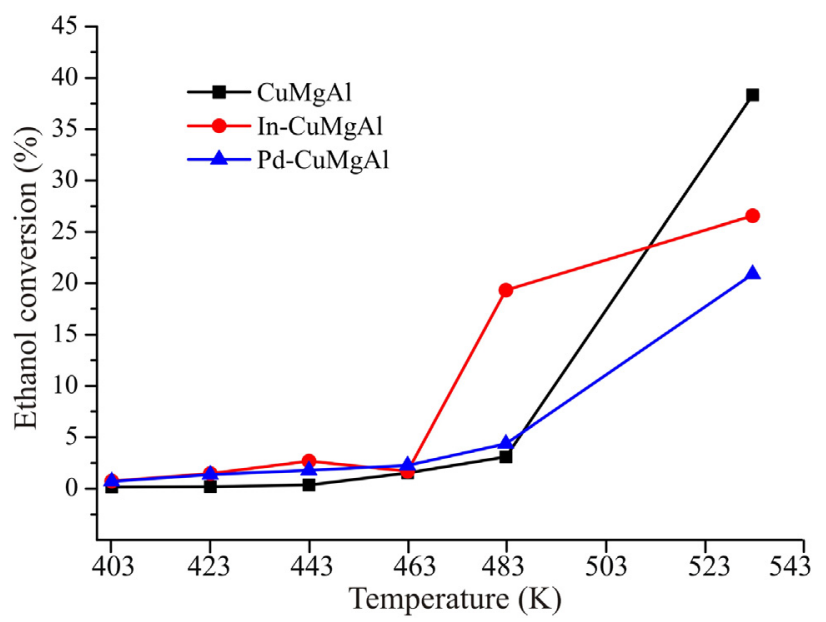

Fig. 1. Ethanol conversion over $\mathrm{CuMgAl}$, In-CuMgAl and $\mathrm{Pd}-\mathrm{CuMgAl}$ catalysts. 


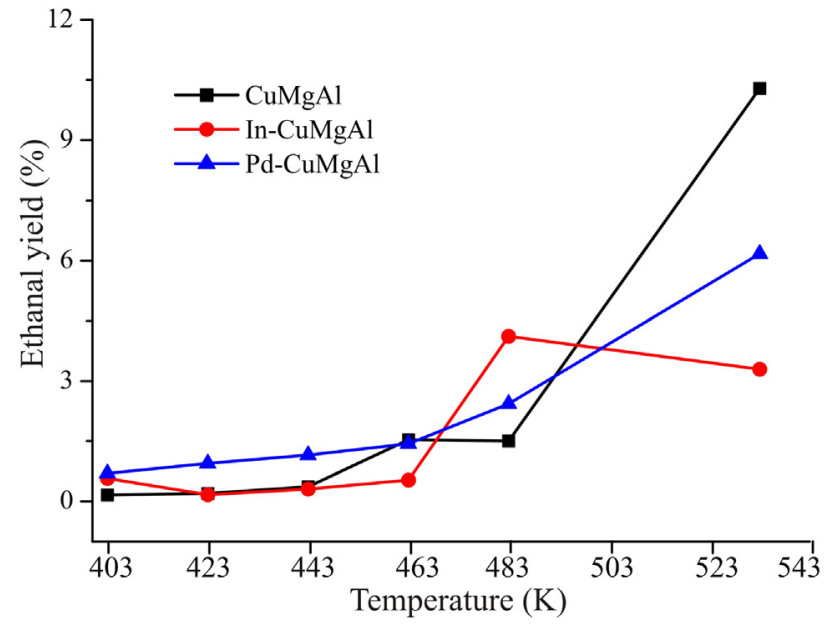

Fig. 2. Ethanal yield over $\mathrm{CuMgAl}$, In-CuMgAl and $\mathrm{Pd}-\mathrm{CuMgAl}$ catalysts.

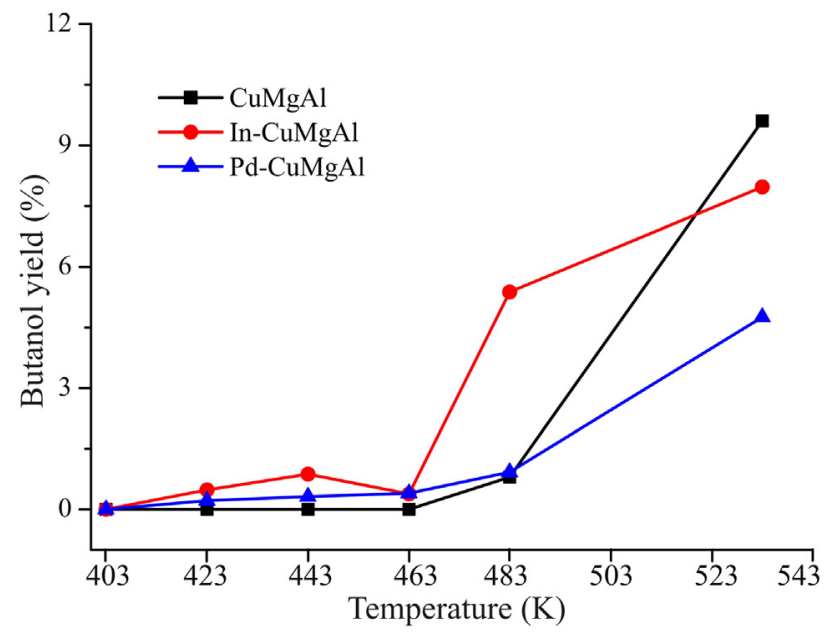

Fig. 3. Butanol yield over $\mathrm{CuMgAl}$, In-CuMgAl and Pd-CuMgAl catalysts.

the catalyst. However, this work was focused on developing catalysts that may promote reactions that may occur at low temperature trying to increase the selectivity towards butanol.

As shown in Scheme 1 ethanal from the dehydrogenation of ethanol is the first product of the reaction. The dehydrogenation reaction in addition to providing ethanal for the next step of the aldol reaction, results in the formation of hydrogen which is necessary for

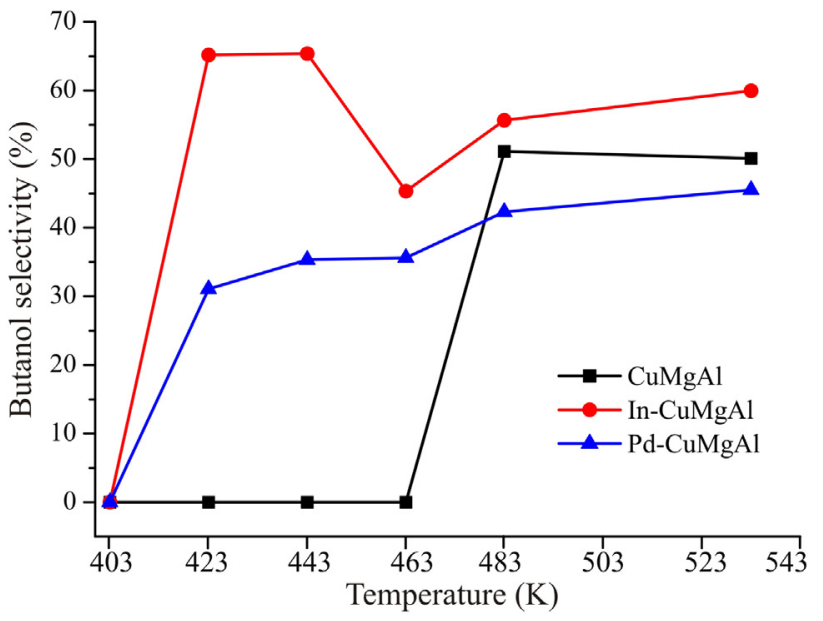

Fig. 4. Butanol selectivity over $\mathrm{CuMgAl}$, In-CuMgAl and $\mathrm{Pd}-\mathrm{CuMgAl}$ catalysts.

hydrogenation of crotonaldehyde and butyraldehyde and consequent butanol formation. In Fig. 2 are shown the ethanal yield for the reaction using the above mentioned catalysts. It can be seen that the addition of palladium to the catalytic materials causes an increase in ethanol dehydrogenation even at low temperatures and higher ethanal yields are observed when compared with the CuMgAl catalyst. On the other hand, In-CuMgAl catalyst does not demonstrate significant ethanal production at temperatures below $483 \mathrm{~K}$, probably due to ethanal consumption for butanol formation, as will be demonstrated below.

Fig. 3 shows the butanol yield after reactions. One can observe that with the reference material (CuMgAl) butanol is formed only starting from the temperature of $483 \mathrm{~K}$ and reaches about $10 \%$ yield at the temperature of $533 \mathrm{~K}$. At this temperature $(533 \mathrm{~K})$ approximately $60 \mathrm{~mL}$ of gas was collected from the reactor, and the carbon balance was higher than $90 \%$ (gas + condensed-phase). On the other hand, catalysts containing indium (In-CuMgAl) or palladium (Pd-CuMgAl) are able to promote the butanol synthesis even at temperatures as low as $423 \mathrm{~K}$.

The increase in butanol yield at a lower temperature using Pd$\mathrm{CuMgAl}$ or In-CuMgAl can be associated with the increase of the catalyst hydrogen-transfer capacity that makes faster all five steps of the reaction (Scheme 1). The intermediate compounds, 3-hydroxybutanol and crotonaldehyde, are very short lived and are not detected in the reaction mixture. The influence of $\mathrm{H}$-transfer metals such as $\mathrm{Cu}, \mathrm{Pd}$, or In is clear and lower temperatures are necessary for the reaction to occur. However, the Guerbet reaction requires $>573 \mathrm{~K}$ to occur using only $\mathrm{MgAl}$ oxides. With $\mathrm{Cu}$, they occur at $483-533 \mathrm{~K}$, and with $\mathrm{Pd}$ or In at $423-443 \mathrm{~K}$, with large energy saving. As the In or Pd-loading is quite

Table 1

Comparison of our data with Literature data using heterogeneous oxides for ethanol conversion.

\begin{tabular}{|c|c|c|c|c|c|c|c|}
\hline Catalyst & Surface area $\left(\mathrm{m}^{2} \mathrm{~g}^{-1}\right)$ & Reaction temperature (K) & Reaction time (h) & EtOH conversion (\%) & ButOH selectivity (\%) & ButOH yield (\%) & Ref. \\
\hline $\mathrm{CuMgAl}$ & 127 & 533 & 5 & 38.0 & 50.0 & 9.6 & \\
\hline CuMgAl & 127 & 573 & 5 & 46.5 & 62.2 & 15.2 & \\
\hline Pd-CuMgAl & 48 & 443 & 5 & 1.8 & 35.3 & 0.3 & \\
\hline Pd-CuMgAl & 48 & 533 & 5 & 20.9 & 45.5 & 4.8 & \\
\hline In-CuMgAl & 92 & 443 & 5 & 3.0 & 65.4 & 1.0 & \\
\hline In-CuMgAl & 92 & 533 & 5 & 26.6 & 60.0 & 8.0 & \\
\hline Pd5MgAlO & 187 & 473 & 5 & 3.8 & 72,7 & - & [17] \\
\hline $\mathrm{Ni}_{4} \mathrm{MgAlO}$ & 206 & 473 & - & 18.7 & 55.2 & - & [14] \\
\hline $\mathrm{Cu}_{5} \mathrm{MgAl}_{(3)} \mathrm{O}$ & 150 & 473 & 5 & 4.1 & 40.3 & - & [15] \\
\hline $8 \mathrm{Ni} / \mathrm{Al}$ & 152 & 503 & 11 & 25.3 & 52,4 & - & [16] \\
\hline $20.7 \% \mathrm{Ni} / \mathrm{Al}_{2} \mathrm{O}_{3}$ & 289 & 523 & 72 & 25.0 & 80.0 & - & [18] \\
\hline $8 \% \mathrm{Ni} / \gamma$-alumina & 128 & 523 & - & 35.0 & 61.7 & 21.6 & [9] \\
\hline $\mathrm{MgO}-\mathrm{Al}_{2} \mathrm{O}_{3}$ & 200 & 573 & - & $\sim 42.0$ & $\sim 50.0$ & - & {$[8]$} \\
\hline Cu10Ni10-PMO & 256 & 593 & 6 & 56.5 & 70.0 & 22.2 & [10] \\
\hline $\mathrm{MgO}-\mathrm{Al}_{2} \mathrm{O}_{3}$ & - & 623 & - & 62.0 & 42.0 & - & [19] \\
\hline $\mathrm{Ca}_{3}\left(\mathrm{PO}_{4}\right)_{2} \mathrm{Ca}(\mathrm{OH})_{2}$ & 82 & 673 & - & $>30.0$ & $\sim 54.0$ & - & [20] \\
\hline
\end{tabular}




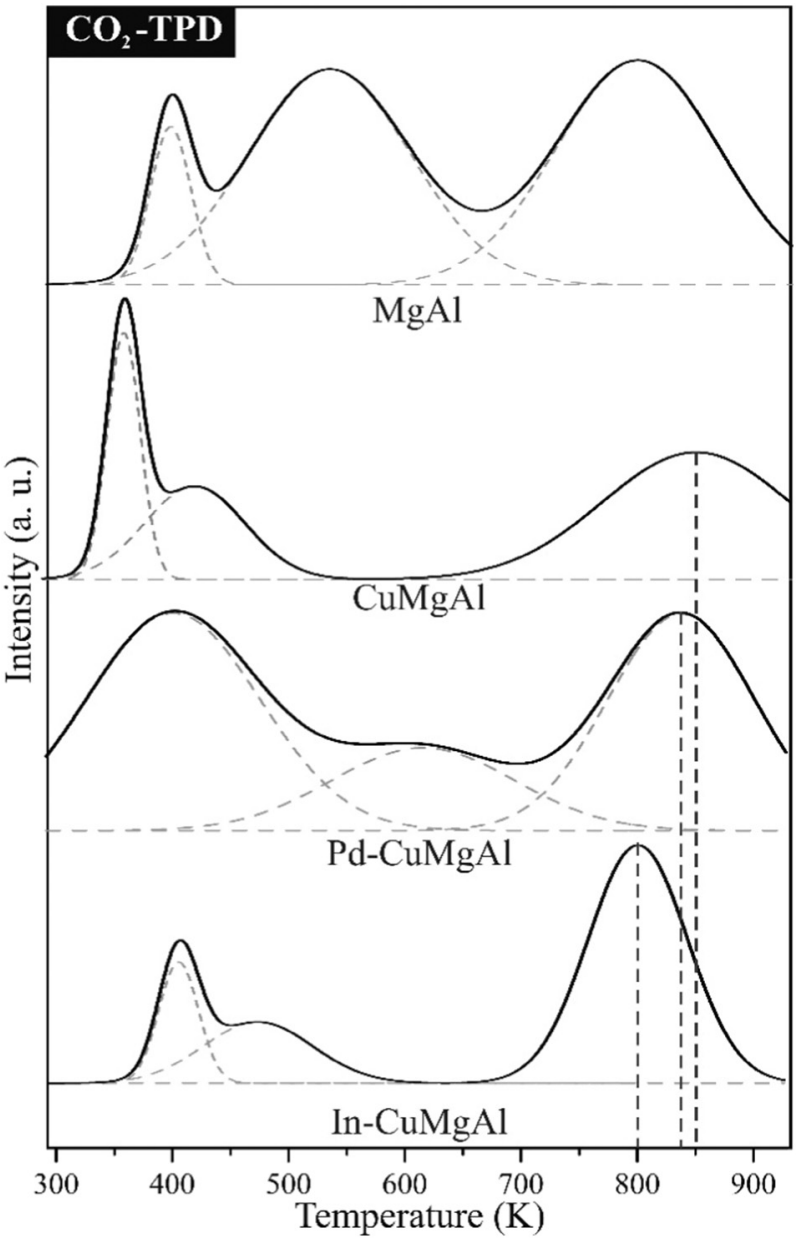

Fig. 5. $\mathrm{CO}_{2}$-TPD profiles of the mixed-oxide catalysts.

low $(<1 \%)$ its use is sustainable. This suggests that the stages of dehydrogenation and hydrogenation are the rate determining steps. Therefore, addition of metals that favor such steps, namely copper, palladium or indium, improves the performance of basic metal oxide catalysts making this reaction possible even at low temperatures, as shown in Fig. 3.

As described by various authors, different heterogeneous oxides derived from hydrotalcites or hydroxyapatite show distinct conversions and selectivity for butanol. Usually reactions are carried out at temperatures ranging from 473 to $673 \mathrm{~K}$ (Entries 7-16, Table 1). In a general analysis, it can be observed that the increase of the reaction temperature significantly increases the ethanol conversion rate. In our work we have targeted high selectivity and tried to reduce the temperature as much as possible (Entries 3 and 5 ) for energy saving. The selectivity for butanol is driven by different parameters, such as the composition of the catalytic material, the reaction temperature and catalyst surface properties. Table 1 compares our results (Entries 1-6) with some selected literature data. It is quite evident that the addition of palladium or indium significantly decreases the temperature required for the reaction to occur.

As shown in Fig. 4 good selectivity for butanol was achieved for all our catalysts in the temperature range $423-573 \mathrm{~K}$. But in reactions carried out at temperatures above $483 \mathrm{~K}$ secondary reactions and undesirable products are formed together with butanol increasing its production cost due to both high reaction temperature and more energy required for product separation. Below $483 \mathrm{~K}$, only butanol and ethanal are detected in the liquid phase for the In-CuMgAl and CuMgAl catalysts, while with Pd-CuMgAl, small amounts of ethyl acetate are also formed. Therefore, the separation of products is much easier. An

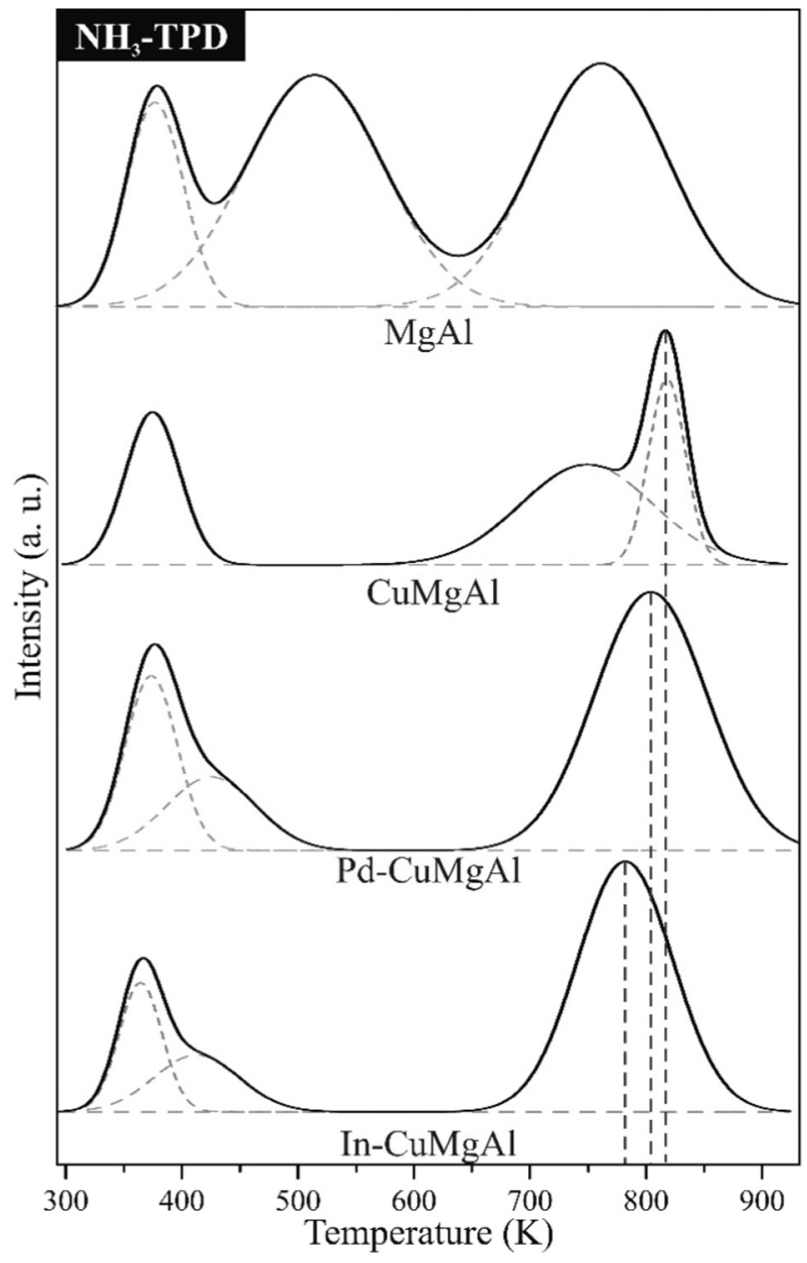

Fig. 6. $\mathrm{NH}_{3}$-TPD profiles of the mixed-oxide catalysts.

Table 2

Number of basic and acid sites of different strength for MgAl, CuMgAl, Pd$\mathrm{CuMgAl}$ and In-CuMgAl mixed oxides, derived from TPD-NH $\mathrm{N}_{3}$ and TPD- $\mathrm{CO}_{2}$.

\begin{tabular}{|c|c|c|c|c|c|c|c|c|}
\hline \multirow[t]{2}{*}{ Catalyst } & \multicolumn{4}{|c|}{$\mathrm{CO}_{2}$ desorbed $\left(\mu \mathrm{mol} \mathrm{g}{ }^{-1}\right)$} & \multicolumn{4}{|c|}{$\mathrm{NH}_{3}$ desorbed $\left(\mu \mathrm{mol} \mathrm{g}{ }^{-1}\right)$} \\
\hline & W & M & S & Total & W & M & $\mathrm{S}$ & Total \\
\hline $\mathrm{MgAl}$ & 5.3 & 28.6 & 24.1 & 57.9 & 17.5 & 48.1 & 48.3 & 113.9 \\
\hline CuMgAl & 19.4 & 34.1 & 65.0 & 118.6 & 68.6 & 109.8 & 59.5 & 237.9 \\
\hline Pd-CuMgAl & 38.1 & 16.7 & 31.9 & 86.7 & 14.5 & 10.6 & 44.4 & 69.4 \\
\hline In-CuMgAl & 9.6 & 13.4 & 47.1 & 70.1 & 25.2 & 21.8 & 105.6 & 152.6 \\
\hline
\end{tabular}

W: weak; M: medium; S: high strength.

interesting (65\%) selectivity for butanol can be observed at $423 \mathrm{~K}$ for In-CuMgAl catalysts. Although the yield and conversion are not high, this catalyst can be considered as an excellent candidate for studies in flow reactors (in progress) in which ethanol can be recovered and recycled increasing the overall yield of the reaction. This process could be very promising if executed inside sugarcane mills, where butanol production could be performed using the ethanol production infrastructure and also taking advantage of the low cost energy available from bagasse combustion.

\subsection{Catalyst characterization}

The basicity of the mixed-oxides used in this work was determined using $\mathrm{CO}_{2}$-TPD technique (Fig. 5). This technique gives information about both the strength and number of basic sites which can be deduced from the desorption temperature and the peak area, respectively. LDHs 
oxides show at least three peaks, the first one between 350 and $450 \mathrm{~K}$ related to weak basic strength sites. These basic sites are associated with surface hydroxyl groups remaining after calcination. The second peak usually between 450 and $650 \mathrm{~K}$ is attributed to medium-strength Lewis sites and related to $\mathrm{Mg}^{2-}-\mathrm{O}^{2-}$ and $\mathrm{Al}^{3+}-\mathrm{O}^{2-}$ acid-base pairs in the catalyst. Lastly, peaks at $700-900 \mathrm{~K}$ are attributed to strong Lewis basic sites and related to the presence of low-coordinated $\mathrm{O}^{2-}$ species $[17,21,22]$.

In the same way, desorption by TPD- $\mathrm{NH}_{3}$ showed at least 3 desorption peaks at $350-450 \mathrm{~K}, 450-650 \mathrm{~K}$ and $700-900 \mathrm{~K}$ also related to weak-medium- and strong acid sites, respectively (Fig. 6). Figs. 5 and 6 clearly show that the addition of different metals to the starting $\mathrm{MgAl}$ materials, causes a net change in the total number and strength of acid and base catalytic sites modifying, thus, the catalytic activity of the oxides. The change is caused by the different characteristics of the added cations, as ionic radius and electronegativity.

In our case, the signal extending from 300 to ca. $900 \mathrm{~K}$ (Figs. 5 and 6) in the profile of MgAl materials (top profile in both Figs. 5 and 6), was deconvoluted into three desorption peaks to calculate the number of sites with weak (W), medium (M), and high strength (S). The total number and the relative number of such sites are shown in Table 2. Copper addition to the MgAl material increases both weak and high strength basic sites (second profile from the top in Fig. 5), with consequent increases in the total number of catalytic sites (most likely associated to the strong sites), which justify the improvement in the catalytic activity of this catalyst. On the other hand, the addition of palladium or indium while has not a great influence on the total number of strong sites, decreases the temperature of desorption of strong basic sites, that may influence the activity of the catalyst and explain why they work at lower temperature.

The total amount of acid sites increases with copper insertion (Table 2). However, the inclusion of palladium or indium ions while decreases the total acidity of the oxides due to a decrease in the number of weak and medium strength acid sites, increases the number of strong acid sites, most likely the most active in catalysis [23,24].

In-CuMgAl oxide showed a decrease in the number of weak and medium strength acid and basic sites. But the indium presence increases the amount of high strength acid sites and high strength basic sites and moves them towards lower temperature. The reaction using this catalyst achieved the lowest ethanal yield at temperatures between 423 and $443 \mathrm{~K}$ and the highest butanol yield, meaning that the acetaldehyde was consumed by the formation of butanol already at such low temperature, the lowest ever documented. This observation indicates that high strength sites and the desorption temperature, together with a good $\mathrm{H}$ transfer ability, play an important role in this reaction at low temperature.

\section{Conclusion}

The results of this work demonstrate that mixed oxides derived from hydrotalcites, cheap and easy to synthesize, can be modified with metals such as $\mathrm{Cu}, \mathrm{Pd}$, In and catalysts suitable for conversion of ethanol to butanol in mild conditions are produced. Presence of indium or palladium in the catalyst strongly influences the temperature of reaction so that it was possible to obtain butanol at temperature as low as $423 \mathrm{~K}$, an absolute novelty. Although ethanol is converted into butanol at low temperatures at a rate lower than $5 \%$, by-products production is very low and separation costs (economic and energetic) are also low. Using a continuous reactor, it would be possible to take advantage of the low temperature conversion. At $533 \mathrm{~K}$ a better conversion is obtained (26.6\%) with $60 \%$ selectivity, but the reaction mixture is more complex and more energy is required for product separation.

\section{Acknowledgements}

Authors (OMP and MB) would like to thank FAPESP (process: 2016/
15575-7) and VALBIOR-Apulian Region is thanked for the use of equipment.

\section{References}

[1] J.M.R. Gallo, J.M.C. Bueno, U. Schuchardt, Catalytic transformations of ethanol for biorefineries, J. Braz. Chem. Soc. 25 (2014) 2229-2243, http://dx.doi.org/10.5935/ 0103-5053.20140272.

[2] C. Angelici, B.M. Weckhuysen, P.C.A. Bruijnincx, Chemocatalytic conversion of ethanol into butadiene and other bulk chemicals, ChemSusChem 6 (2013) 1595-1614, http://dx doi.org/10.1002/cssc.201300214.

[3] D.L. Carvalho, R.R. De Avillez, M.T. Rodrigues, L.E.P. Borges, L.G. Appel, Mg and Al mixed oxides and the synthesis of n-butanol from ethanol, Appl. Catal. A Gen. 415-416 (2012) 96-100, http://dx.doi.org/10.1016/j.apcata.2011.12.009.

[4] W.R. da S. Trindade, R.G. dos Santos, Review on the characteristics of butanol, its production and use as fuel in internal combustion engines, Renew. Sust. Energ. Rev. 69 (2017) 642-651, http://dx.doi.org/10.1016/j.rser.2016.11.213.

[5] T. Riittonen, K. Eränen, P. Mäki-Arvela, A. Shchukarev, A.R. Rautio, K. Kordas, N. Kumar, T. Salmi, J.P. Mikkola, Continuous liquid-phase valorization of bio-ethanol towards biobutanol over metal modified alumina, Renew. Energy 74 (2014) 369-378, http://dx.doi. org/10.1016/j.renene.2014.08.052.

[6] M.O.S. Dias, L.G. Pereira, T.L. Junqueira, L.G. Pavanello, M.F. Chagas, O. Cavalett, R. Maciel Filho, A. Bonomi, Butanol production in a sugarcane biorefinery using ethanol as feedstock. Part I: integration to a first generation sugarcane distillery, Chem. Eng. Res. Des. 92 (2014) 1441-1451, http://dx.doi.org/10.1016/j.cherd.2014.04.030.

[7] S. Cimino, L. Lisi, S. Romanucci, Catalysts for conversion of ethanol to butanol: effect of acid-base and redox properties, Catal. Today (2017), http://dx.doi.org/10.1016/j.cattod. 2017.08.035.

[8] K.K. Ramasamy, M. Gray, H. Job, D. Santosa, X.S. Li, A. Devaraj, A. Karkamkar, Y. Wang, Role of calcination temperature on the hydrotalcite derived $\mathrm{MgO}-\mathrm{Al}_{2} \mathrm{O}_{3}$ in converting ethanol to butanol, Top. Catal. 59 (2016) 46-54, http://dx.doi.org/10.1007/s11244-015 0504-8.

[9] H.S. Ghaziaskar, X. Chunbao, One-step continuous process for the production of 1-butanol and 1-hexanol by catalytic conversion of bio-ethanol at its sub-/supercritical state, RSC Adv. 3 (2013) 4271-4280, http://dx.doi.org/10.1039/c3ra00134b.

[10] Z. Sun, A.C. Vasconcelos, G. Bottari, M.C.A. Stuart, G. Bonura, C. Cannilla, F. Frusteri, K. Barta, Efficient catalytic conversion of ethanol to 1-butanol via the Guerbet reaction over copper- and nickel-doped porous, ACS Sustain. Chem. Eng. 5 (2017) 1738-1746, http://dx.doi.org/10.1021/acssuschemeng.6b02494.

[11] S. Abelló, F. Medina, D. Tichit, J. Pérez-Ramírez, J.C. Groen, J.E. Sueiras, P. Salagre, Y. Cesteros, Aldol condensations over reconstructed Mg-Al hydrotalcites: structure-activity relationships related to the rehydration method, Chem. Eur. J. 11 (2005) 728-739, http://dx.doi.org/10.1002/chem.200400409.

[12] G.S. Macala, T.D. Matson, C.L. Johnson, R.S. Lewis, A.V. Iretskii, P.C. Ford, Hydrogen transfer from supercritical methanol over a solid base catalyst: a model for lignin depolymerization, ChemSusChem 2 (2009) 215-217, http://dx.doi.org/10.1002/cssc. 200900033.

[13] F. Hosoglu, J. Faye, K. Mareseanu, G. Tesquet, P. Miquel, M. Capron, O. Gardoll, J.F. Lamonier, C. Lamonier, F. Dumeignil, High resolution NMR unraveling Cu substitution of Mg in hydrotalcites-ethanol reactivity, Appl. Catal. A Gen. 504 (2015) 533-541, http://dx.doi.org/10.1016/j.apcata.2014.10.005.

[14] J. Pang, M. Zheng, L. He, L. Li, X. Pan, A. Wang, X. Wang, T. Zhang, Upgrading ethanol to n-butanol over highly dispersed Ni-MgAlO catalysts, J. Catal. 344 (2016) 184-193, http://dx.doi.org/10.1016/j.jcat.2016.08.024.

[15] I.C. Marcu, D. Tichit, F. Fajula, N. Tanchoux, Catalytic valorization of bioethanol over CuMg-Al mixed oxide catalysts, Catal. Today 147 (2009) 231-238, http://dx.doi.org/10. 1016/j.cattod.2009.04.004.

[16] T.L. Jordison, C.T. Lira, D.J. Miller, Condensed-phase ethanol conversion to higher alcohols, Ind. Eng. Chem. Res. 54 (2015) 10991-11000, http://dx.doi.org/10.1021/acs. iecr.5b02409.

[17] I.C. Marcu, N. Tanchoux, F. Fajula, D. Tichit, Catalytic conversion of ethanol into butanol over M-Mg-Al mixed oxide catalysts (M = Pd, Ag, Mn, Fe, Cu, Sm, Yb) obtained from LDH precursors, Catal. Lett. 143 (2013) 23-30, http://dx.doi.org/10.1007/s10562-0120935-9.

[18] T. Riittonen, E. Toukoniitty, D.K. Madnani, A.-R. Leino, K. Kordas, M. Szabo, A. Sapi, K. Arve, J. Wärnå, J.-P. Mikkola, One-pot liquid-phase catalytic conversion of ethanol to 1-butanol over aluminium oxide-the effect of the active metal on the selectivity, Catalysts 2 (2012) 68-84, http://dx.doi.org/10.3390/catal2010068.

[19] K.K. Ramasamy, M. Gray, H. Job, C. Smith, Y. Wang, Tunable catalytic properties of bifunctional mixed oxides in ethanol conversion to high value compounds, Catal. Today 269 (2016) 82-87, http://dx.doi.org/10.1016/j.cattod.2015.11.045.

[20] F.C. Meunier, S. Julien, T.-S. Frédéric, Unraveling the mechanism of catalytic reactions through combined kinetic and thermodynamic analyses: application to the condensation of ethanol, C. R. Chim. 18 (2015) 345-350, http://dx.doi.org/10.1016/j.crci.2014.07. 002.

[21] D. Wang, X. Zhang, C. Liu, T.T. Cheng, W. Wei, Y. Sun, Transition metal-modified mesoporous Mg-Al mixed oxides: stable base catalysts for the synthesis of diethyl carbonate from ethyl carbamate and ethanol, Appl. Catal. A Gen. 505 (2015) 478-486, http://dx. doi.org/10.1016/j.apcata.2015.04.034.

[22] D. Gabriëls, W.Y. Hernández, B. Sels, P. Van Der Voort, A. Verberckmoes, Review of catalytic systems and thermodynamics for the Guerbet condensation reaction and challenges for biomass valorization, Catal. Sci. Technol. 5 (2015) 3876-3902, http://dx.doi. org/10.1039/C5CY00359H.

[23] P. Carniti, A. Gervasini, F. Bossola, V. Dal, Environmental Cooperative action of Brønsted and Lewis acid sites of niobium phosphate catalysts for cellobiose conversion in water, Appl. Catal. B Environ. 193 (2016) 93-102, http://dx.doi.org/10.1016/j.apcatb.2016.04. 012 .

[24] M. Ventura, M. Aresta, A. Dibenedetto, Selective aerobic oxidation of 5-(hydroxymethyl) furfural to 5-formyl-2-furancarboxylic acid in water, ChemSusChem (2016) 1096-1100, http://dx.doi.org/10.1002/cssc.201600060. 